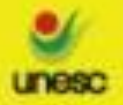

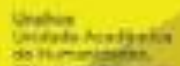

unesc

anconitino

\title{
O TRABALHO PEDAGÓGICO DOS PROFESSORES DA ESCOLA CAMPO: \\ EXPECTATIVAS CONSTRUÍDAS POR ESTAGIÁRIOS DO CURSO DE \\ PEDAGOGIA DA UNESC.
}

\section{THE PEDAGOGICAL WORK OF SCHOOL TEACHERS FIELD: EXPECTATIONS CONSTRUCTED BY TRAINNES OF THE UNESC PEDAGOGY COURSE.}

\author{
Ana Paula dos Santos Matias ${ }^{1}$ \\ Ricardo Luiz de Bittencourt ${ }^{2}$
}

\begin{abstract}
RESUMO: A formação inicial do professor é um processo importante, visto que agrega diversos elementos, dentre eles o estágio obrigatório. $\mathrm{O}$ objetivo geral dessa pesquisa foi "compreender quais as expectativas dos estagiários (as) do curso de pedagogia da Unesc em relação ao trabalho desenvolvido pelo professor (a) dentro da sala de aula nos anos iniciais." Como referenciais teóricos utilizam-se Nóvoa (1995-2002), Garcia (1999), Tardif (2014) entre outros, apresentando a perspectiva da formação do professor. Pimenta (2012), Lima (2008 - 2012), entre outros ressaltam a importância do estágio obrigatório. A coleta de dado foi desenvolvida pela aplicação de um questionário contendo sete perguntas, com acadêmicos da sétima fase do curso de Pedagogia da UNESC, no ano de 2018, no município de CriciúmaSC. Com isso, os sujeitos afirmam que o estágio obrigatório contribui para a escolha da modalidade em que desejam atuar. Reconhecem que é oportunidade de adquirir experiência profissional dentro da sala de aula, observando as práticas pedagógicas dos professores e refletindo sobre elas. Confirmam que é o momento de fazer a articulação da teoria aprendida na universidade com a prática nas escolas, superando as expectativas. Portanto, o estágio obrigatório é um elemento oportuno na formação do acadêmico, proporcionando experiências e aprendizagem.
\end{abstract}

PALAVRAS CHAVE: Formação de professores. Estágio Obrigatório. Teoria e Prática.

ABSTRACT: The initial formation of the teacher is an important process, because it adds several elements, among them the obligatory stage. The general objective of this research was to "understand the expectations of the trainees of the Unesc pedagogy course in relation to the work developed by the teacher within the classroom in the initial years." Theoretical references are Nóvoa ( 1995-2002), Garcia (1999), Tardif (2014) among others, presenting the teacher training perspective. Pimenta (2012), Lima (2008 - 2012), and others emphasize the importance of obligatory stage. The data collection was developed by the application of a questionnaire containing seven questions, with academics from the seventh phase of the

\footnotetext{
${ }^{1}$ Graduanda em Pedagogia - UNESC. paulinha-matias@ hotmail.com

${ }^{2}$ Orientador Doutor em Educação. Universidade do Extremo Sul Catarinense/UNESC. rlb@unesc.net Saberes Pedagógicos, Criciúma, v. 3, n², julho/dezembro 2019.- Curso de Pedagogia - UNESC
} 


\section{SABERES PEDAGÓGICOS}

Revista do Curso de Graduaçāo de Pedagogia - Unesc

ISSN $2526-4559$

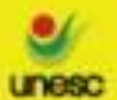

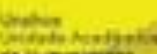

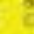

Pedagogy course of UNESC, in the year of 2018, in the municipality of Criciuma-SC. With this, the subjects affirm that the obligatory stage contributes to the choice of modality in which they wish to act. They recognize that it is an opportunity to acquire professional experience within the classroom, observing the teachers' pedagogical practices and reflecting on them. They confirm that it is time to articulate the theory learned at university with practice in schools, surpassing expectations. Therefore, the obligatory stage is an opportune element in the formation of the academic, providing experiences and learning.

KEYWORDS: Teacher training. Obligatory stage. Theory and practice.

\section{INTRODUÇÃO}

Esse artigo trata de uma pesquisa sobre o estágio obrigatório dos anos iniciais no curso de Pedagogia da Unesc, elemento importante na formação do estagiário, oportunizando o contato mais direto com a escola e com a sala de aula.

A escolha do tema "o trabalho pedagógico dos professores da escola campo: expectativas construídas por estagiários do curso de pedagogia da unesc", veio durante a socialização dos estágios dos anos iniciais, cuja maioria dos acadêmicos (as) foram surpreendidos por uma prática do professor (a) regente ainda tradicional, como o uso do livro didático e a memorização dos conteúdos, exercendo um papel de transmissor. Sendo assim, surgiu a necessidade dessa pesquisa, cujo problema é: “o trabalho pedagógico desenvolvido pelo professor (a) da escola campo atende as expectativas dos estagiários (as) do curso de Pedagogia da Unesc?”

O artigo está estruturado em três seções: a primeira seção faz uma introdução do trabalho. A segunda trata da formação do professor, em seguida se discute o estágio obrigatório na formação do professor. Logo após relata-se o estágio dentro do curso de Pedagogia da Unesc.

Posteriormente, apresenta-se a metodologia e análise de dados, objetivando encontrar a perspectiva das acadêmicas com o estágio supervisionado nos anos iniciais. E por fim, exposto as conclusões e as referências bibliográficas que deram base a esse artigo. 


\title{
2 FORMAÇÃO DO PROFESSOR
}

Nesta seção serão apresentadas as principais ideias dos teóricos em relação à temática formação do professor. Nóvoa (1995; 2002); Tardif (2014); Garcia (1999); Ghedin, Oliveira, Almeida (2015); Pimenta (2012); Ghedin, Almeida, Leite (2008).

A formação do professor é um processo contínuo, que acontece durante sua trajetória docente, pois segundo Tardif (2014, p. 287) a "formação dos professores supõe um continuum [sic] no qual, durante toda a carreira docente, fases de trabalho devem alternar com fases de formação contínua [...]". Sendo assim, a formação do professor é um processo que envolve toda sua carreira profissional ultrapassando a formação inicial, criando habilidades para sua docência. Já Garcia (1999, p. 26), conceitua:

\begin{abstract}
A formação do professor é uma área de conhecimentos, investigação e de proposta teórica e práticas, que no âmbito da Didáctica [sic] e da Organização escolar, estuda os processos através do quais os professores - em formação ou em exercício - se implicam individualmente ou em equipa [sic], em experiência de aprendizagem através dos quais adquirem ou melhoram seus conhecimentos, competências e disposições, e que lhe permite intervir profissionalmente do desenvolvimento do seu ensino, currículo, e da escola, com o objectivo [sic] de melhorar a qualidade da educação que os alunos recebem.
\end{abstract}

A formação do professor é um processo que não deve ser pensado apenas para o exercício do trabalho. É preciso buscar uma identidade profissional, que estará sendo construída durante sua docência, estabelecendo relação com sua prática individual e também nas relações dos grupos dentro da instituição. Favorecendo assim, o ensino de qualificação para todos os sujeitos.

Para Nóvoa (1995), a formação de professores está relacionada com o desenvolvimento pessoal, profissional, e organizacional, ou seja, a formação não pode desconsiderar esses aspectos. Sendo assim, é preciso ter diferentes habilidades pessoais, assumir um papel contínuo e coletivo na construção do conhecimento profissional e articular com a realidade da instituição. Conforme Nóvoa (1995, p. 3 e 4):

A formação de professores tem ignorado, sistematicamente o desenvolvimento pessoal, confundindo 'formar e forma-se', não compreendendo que a lógica da actividade [sic] educativa nem sempre coincide com as dinâmicas próprias da

Saberes Pedagógicos, Criciúma, v. 3, n², julho/dezembro 2019.- Curso de Pedagogia - UNESC 

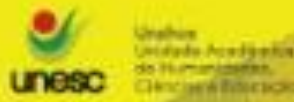

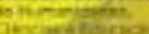

formação. Mas também não tem valorizado uma articulação entre a formação e os projectos [sic] das escolas, consideradas como organizações dotadas de margens de autonomia e de decisão de dia para dia mais importantes. Estes dois 'esquecimentos' inviabilizam que a formação tenha como eixo de referência o desenvolvimento profissional dos professores, na dupla perspectiva do professor individual e do colectivo [sic] docente.

No desenvolvimento pessoal, o professor precisa construir diferentes habilidades em relação à teoria e a prática dentro da sala de aula, adquirindo experiência e autonomia na sua profissão. O autor ainda acrescenta que "estar em formação implica um investimento pessoal, um trabalho livre e criativo sobre os percursos e os projectos [sic] próprios, com vista à construção de uma identidade, que é também uma identidade profissional." (NÓVOA, 1995, p. 4). O desenvolvimento profissional é construído durante toda carreira docente. Segundo Nóvoa (1995, p. 6):

Práticas de formação contínua organizadas em torno dos professores individuais podem ser úteis para a aquisição de conhecimentos e de técnicas, mas favorecem o isolamento e reforçam uma imagem dos professores como transmissores de um saber produzido no exterior da profissão.

É preciso, que o docente durante seu processo de formação, trabalhe no coletivo com outros profissionais. Nóvoa (2002) aponta que esse desenvolvimento deve estar vinculado com as instituições e seus projetos, fazendo que os professores sejam autores nesse desenvolvimento.

Já no desenvolvimento organizacional, a escola precisa da formação do professor e de seus diferentes saberes, para ocorrer uma verdadeira mudança. Nóvoa (2002, p. 61) descreve que o "desafio consiste em conceber a escola como um ambiente educativo, onde trabalhar e formar não sejam atividades distintas." Neste sentido, é preciso que o professor esteja aberto ao diálogo, troca de experiências compreendendo que a escola é um espaço de formação de diferentes conhecimentos.

Considerando que o professor em sua formação inicial já possui saberes sociais, o autor afirma que o "professor é, antes de tudo, alguém que sabe alguma coisa e cuja função consiste em transmitir esse saber a outro." (TARDIF, 2014, p. 31). Entretanto, Ghedin; Almeida; Leite (2008, p. 30) dizem que: 


\section{SABERES PEDAGÓGICOS}

Revista do Curso de Graduaçāo de Pedagogia - Unesc

ISSN 2526-4559

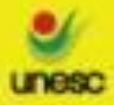

Thistonest

ton

É preciso superar um modelo de formação que considera o professor apenas como transmissor de conhecimentos, que se preocupa somente com a formação de atitudes de obediência, de passividade e de subordinação nos alunos, que trate os alunos como assimiladores de conteúdos, a partir de simples práticas de adestramento que tomam como mote as memorizações e repetições de conhecimentos que pouco têm a ver com a realidade dos alunos.

Conforme Ghedin; Oliveira e Almeida (2015), o estágio pode ser considerado dentro da formação inicial uns dos primeiros contatos com a teoria e a prática e assim ampliando as práxis durante esse período. Diante dessas reflexões, entende-se que formação inicial são capacidades que o profissional irá desenvolver ao longo de sua carreira, sendo relevante para a sua prática pedagógica.

Segundo Pimenta (2012, p. 65), "um curso de formação estará dando conta do aspecto prático da profissão na medida em que possibilite o treinamento, em situações experimentais, de determinadas habilidades consideradas a priori como necessárias ao bom desempenho do docente." Entende-se então que é preciso desenvolver diversas habilidades durante sua formação profissional, desenvolvendo situações de aprendizagens diferentes, contribuindo à aprendizagem dos alunos.

O estágio é favorável para formação inicial do professor pois tem "por objetivo formar o profissional docente como intelectual crítico-reflexivo, possibilitando a construção dos saberes docentes necessários para compreender e atuar na realidade educacional e propor alternativas pedagógicas.” (GHEDIN, ALMEIDA, LEITE, 2008, p. 37).

Teoria e prática precisam estar associadas, pois não existe uma sem a outra. Para Ghedin, Almeida, Leite (2008, p. 15) “a formação inicial e contínua não pode ignorar esses processos, pois são realidades complexas que fundamentam a aprendizagem profissional dos docentes [...].” Sendo assim, esses aspectos contribuem na formação do professor.

A formação continuada deve proporcionar perspectivas inovadoras, valorizando seu conhecimento. É importante destacar o desenvolvimento pessoal, e articular o desenvolvimento profissional e organizacional. Conforme Nóvoa (2002, p. 58):

Práticas de formação contínua organizadas em tormo dos professores individuais podem ser úteis para a aquisição de conhecimentos e de técnicas, mas favorecem o isolamento e reforçam uma imagem dos professores como transmissores de um saber produzido no exterior da profissão. Práticas de formação contínua que tomem como referência as dimensões colectivas [sic] contribuem para a emancipação

Saberes Pedagógicos, Criciúma, v. 3, n², julho/dezembro 2019.- Curso de Pedagogia - UNESC 
profissional e para a consolidação de uma profissão que é autónoma na produção dos seus saberes e dos seus valores.

Desse modo, a formação do professor é um processo contínuo, onde se encontra muitos desafios, aprendizagens e melhorias nas atividades pedagógicas. Deve ser vista, como uma produção da identidade profissional, e que somente as experiências do dia a dia não tornará um bom profissional. Portanto, a formação inicial em nível superior começa pela universidade, estágios e deve estar associada à formação continuada que articula o desenvolvimento pessoal, profissional e organizacional.

\section{ESTÁGIO OBRIGATÓRIO NA FORMAÇÃO DO PROFESSOR}

Esta seção tem como objetivo trazer o estágio obrigatório como um elemento importante na formação do professor. Pimenta (2012, p. 27) apresenta um conceito de estágio obrigatório "atividades que os alunos deverão realizar durante o seu curso de formação, junto ao campo futuro de trabalho - as séries iniciais do ensino."

Um dos principais desafios dos acadêmicos do curso de Pedagogia é se deparar com as disciplinas de estágio supervisionado. Conforme as Diretrizes Curriculares Nacionais para o curso de Pedagogia:

\footnotetext{
O estágio curricular pressupõe atividades pedagógicas efetivadas em um ambiente institucional de trabalho, reconhecido por um sistema de ensino, que se concretiza na relação interinstitucional, estabelecida entre um docente experiente e o aluno estagiário, com a mediação de um professor supervisor acadêmico. Deve proporcionar ao estagiário uma reflexão contextualizada, conferindo-lhe condições para que se forme como autor de sua prática, por meio da vivência institucional sistemática, intencional, norteada pelo projeto pedagógico da instituição formadora e da unidade campo de estágio. (BRASIL, 2005, p. 15).
}

Uma das formas de estabelecer relação entre teoria e prática é através do estágio das licenciaturas, denominado como obrigatório e não obrigatório. No curso de formação em Pedagogia, possuem o estágio obrigatório que está previsto como disciplina do currículo, e o não obrigatório que é uma chance de ganhar um bolsa de estudo, oportunizando ao estagiário aproximar-se de modo mais sistemático e contínuo das escolas, dos professores e de suas práticas pedagógicas. Contudo Ghedin, Oliveira, Almeida (2015, p. 40) afirmam que o estágio Saberes Pedagógicos, Criciúma, v. 3, n², julho/dezembro 2019.- Curso de Pedagogia - UNESC 


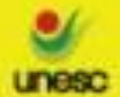

ationention

é um modo de preparar os estagiários a "[...] efetivar as práticas de ser e estar fazendo-se professor."

Inicialmente no estágio obrigatório, o acadêmico começa pela observação de um profissional já formado e de sua turma. De acordo com Pimenta (2012), é preciso inserir o acadêmico para observar o funcionamento, e assim refletir e conhecer a realidade. Isso vem ao encontro de Lima, (2012, p. 53) "conhecer a realidade por ocasião do estágio requer ver além das evidências observáveis." Após a observação, começar a registrar algumas informações da sala e como o professor ministra sua aula e depois dos dados coletados, o acadêmico prepara as aulas para começar a atuar. Conforme Pimenta (2012, p. 105):

A atividade teórica é que possibilita de modo indissociável o conhecimento da realidade e o estabelecimento de finalidades para sua transformação. Mas para produzir tal transformação não é suficiente a atividade teórica, é preciso atuar praticamente.

É importante ter o feedback entre o estagiário e professor regente de sala de aula, pois a troca de experiência é relevante na formação do futuro profissional, conforme Pimenta e Lima (2017), o diálogo entre professor e aluno é principal no processo de estágio, proporcionando aprendizagens e trocas de conhecimentos. Nesse sentido, é um elemento obrigatório, que propicia ao acadêmico o contato com a teoria e a prática.

É durante o estágio que muitos acadêmicos terão o primeiro contato mais orgânico com a sala de aula. Por isso que o estagiário não pode substituir o professor regente, mas acompanhar o profissional e ser acolhido por toda a comunidade escolar, enquanto um aprendiz, sendo assim é necessário conforme Lima (2012) a comunicação entre titular da sala e o acadêmico.

No momento do estágio, o acadêmico põe em prática a teoria que se apropriou, e aproxima-se da habilidade de ser professor, preparando uma aula de acordo com a realidade e a necessidade da turma, fazendo que o aluno seja sujeito do processo de aprendizagem. Como afirma Pimenta (2012), não existe prática sem um pouco de conhecimento teórico. Com isso, o acadêmico pode criar expectativas positivas e negativas em relação ao estágio obrigatório, dependendo de como foi recebido ou como terminou sua experiência. Lima (2012, p. 68) acrescenta “[...] a passagem do estagiário pela escola-campo é um espaço de autoformação e

Saberes Pedagógicos, Criciúma, v. 3, n², julho/dezembro 2019.- Curso de Pedagogia - UNESC 

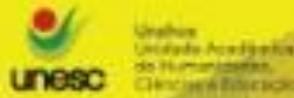

pode acrescentar elementos identitários no tocante à investigação dos fenômenos subjetivos que compõem o ser e o estar na profissão docente."

Uma expectativa dos estagiários perante o estágio obrigatório é construir experiência profissional. Sendo um período de aprendizagem e conhecimento onde o acadêmico trabalha coletivamente com outros profissionais, ganhando experiências e criando sua própria autonomia docente. Conforme Ribeiro e Araújo (2017, p. 1726), as expectativas que não podem faltar nos estagiários são:

O desejo de reconstrução, humildade pedagógica, capacidade de fazer o melhor, pois os mesmos devem empreender esforços visando construir suas práticas pedagógicas em favor da construção de uma qualidade e que responda aos anseios da sociedade em inserira o homem, profissional e emocionalmente, no meio social.

Por outro lado, no estágio o estudante encontra um ambiente com profissionais formados e experientes, ficando muitas vezes inseguros de não ser um bom profissional, não ter domínio da sala, conteúdo entre outros fatores. Para Ghedin, Oliveira, Almeida (2015) o estágio é onde começa o primeiro vínculo entre a teoria aprendida nas universidades e a prática que acontece na sala de aula.

Além disso, o acadêmico depara com um ambiente onde já tem um trabalho iniciado pelo professor titular, e conforme Lima (2012) é preciso dar continuidade sendo que o estagiário, nem se envolveu na elaboração. Ou seja, muitas vezes se limitando a ferramentas usadas pelo professor, tendo dificuldade de inovar. Contudo o que podemos perceber é que as atividades propostas pelos professores titulares, muitas vezes não agregam conhecimentos aos alunos e aos próprios estagiários, por serem atividades meramente tradicionais, na visão de Lombadi (2007, p. 122) as práticas existentes:

\footnotetext{
Não se referem aos problemas, dúvidas e discussões surgidas no e do cotidiano da sala de aula. Isso faz com que o conhecimento da realidade escolar se dê de forma incipiente e não suscite reflexões sobre uma prática crítica e transformadora, o que, consequentemente, impossibilita a reconstrução, ou redefinição, ou mesmo a aprendizagem de teorias que sustentem o trabalho do futuro professor; e, também o repensar do próprio ensino.
}

$\mathrm{O}$ acadêmico quando sai da universidade para a futura atividade docente, possui uma bagagem ampla, que de acordo com Pimenta (2012, p. 163) são, "roteiros, guias, bem Saberes Pedagógicos, Criciúma, v. 3, n² 2, julho/dezembro 2019.- Curso de Pedagogia - UNESC 


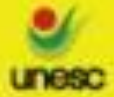

como orientação e preparo dos alunos para irem ao campo", desenvolvem assim, diferentes atividades para enriquecer a aprendizagem dos alunos. Almeida (2007, p. 41) cita que o estágio é "uma oportunidade de fazer a diferença [...]." Contudo, existe uma distância nas práticas educativas desenvolvidas pelos professores da escola campo, para as atividades que os acadêmicos preparam durante o período de estágio. E assim, enfrentam alguns impasses perante aos professores, que acreditam que os estagiários “[...] são portadores de propostas muito novas ou diversas das que as escolas possuem [...].” (PIMENTA, 2012, p. 154).

O estágio obrigatório é um momento de formação, onde não se limita apenas em observar ou reproduzir as práticas do professor, mas sim em aprimorar seus conhecimentos, habilidades e competências para a prática docente, para Pimenta e Lima (2017, p. 196) "[...] os estagiários poderão se envolver com planejamento, execução e avaliação dos instrumentos e de situações para a coleta de dados, adquirindo assim habilidades de pesquisa."

O acadêmico associa o que é estudado no curso de licenciatura, com a realidade existente na escola, porém escuta-se com frequência dos docentes durante o período do estágio obrigatório que teoria e prática são coisas diferentes. Vindo ao desencontro de Pimenta (2012, p. 107), quando diz que "teoria e prática são indissociáveis como práxis." Com isso, criam um receio em relação ao estágio obrigatório. Pacchioni (2000, p. 154) contribui dizendo que "há uma expectativa de corresponderem ás exigências e serem aceitos, como também uma certa adaptação para reproduzirem o que é socialmente determinado [...].” É comum, durante a atuação do estágio, que a metodologia aplicada durante esse período não esteja no seu planejamento, ou seja, algo que não deu certo. Porém é preciso repensar em uma nova estratégia, "precisamos continuamente planejar e replanejar, para que possamos atingir os nossos objetivos, refletir sobre o concreto da realidade escolar e corrigir os desvios do processo.” (PIMENTA; LIMA, 2017, p. 185). Isto é, nem tudo que é planejado poderá ser executado.

O estágio obrigatório nos anos iniciais é indispensável à formação docente, além de ser um processo de aprendizagem constante. Por meio dele, o estagiário (a) consegue rever e ampliar os conhecimentos adquiridos na universidade e ao mesmo tempo produzir novos saberes junto com os professores titulares (as) e alunos (as). Conforme afirma Pimenta e Lima (2017, p. 97):

Saberes Pedagógicos, Criciúma, v. 3, n², julho/dezembro 2019.- Curso de Pedagogia - UNESC 
Essa formação tem por objetivo preparar o estagiário para a realização de atividades nas escolas, com os professores nas salas de aula, bem como para o exercício de análise, avaliação e crítica que possibilite a proposição de projetos de intervenção a partir dos desafios e das dificuldades que a rotina do estágio nas escolas revela.

Além disso, o estagiário consegue aplicar seu plano de aula ou projeto, utilizando materiais diferenciados, considerando a realidade de cada turma. Deste modo é um momento em que os estagiários (as) se sentem professores (as) e começam a criar autonomia profissional. Segundo Lima (2012), o estágio é um ambiente de análise sobre a carreira docente. Assim, o estágio obrigatório é muito importante na vida profissional do acadêmico (a) do curso de Pedagogia. De acordo com Lima (2008, p. 198) o estágio obrigatório tem “caráter passageiro, faz com que ele seja sempre incompleto, porque é no efetivo do magistério que a profissão docente é aprendida de maneira sempre renovada."

Por fim, o estágio supervisionado obrigatório deve ser visto como um elemento essencial na formação do professor. Nele, irá construir autonomia profissional, relacionando os conhecimentos vistos na universidade com a realidade social existente na instituição, e assim construindo sua prática pedagógica.

Na próxima seção, será apresentada a resolução 13/2009 que regulamenta o estágio obrigatório e não obrigatório do curso de Pedagogia da UNESC, tendo o foco principal no estágio obrigatório dos anos iniciais.

\subsection{O estágio no curso de Pedagogia da Unesc}

Através da Resolução, n.13/2009 foi aprovado o estágio obrigatório e não obrigatório do curso de Pedagogia da Universidade do extremo Sul Catarinense - UNESC, a partir do segundo semestre, sendo ainda utilizado nos dias de hoje. De acordo com a Unesc (2009, p. 2):

O estágio deve ser um processo que busca aprofundar conhecimentos e saberes, em consonância como os já adquiridos em todas as disciplinas do curso, visando a uma melhor aproximação do estudante com a realidade profissional em que atuará, por meio de processos prático, reflexivo e investigativo.

Saberes Pedagógicos, Criciúma, v. 3, n², julho/dezembro 2019.- Curso de Pedagogia - UNESC 
Visto que o estágio é uma oportunidade do acadêmico promover o contato com a teoria e a prática, oportunizando ter convívio com a sala de aula de forma mais sistemática da realidade profissional, é exigido a observação e a regência.

A universidade disponibiliza professor orientador de estágio para os acadêmicos, sendo que cada um orientará no máximo quinze alunos. Que conforme Pimenta e Lima (2017, p. 36) é necessário que os “[...] professores orientadores de estágio procedam no coletivo, com seus pares e alunos, a essa apropriação da realidade, para analisá-la e questioná-la criticamente, a luz de teorias. Essa caminhada conceitual certamente será uma trilha para a proposição de novas experiências."

No estágio curricular II dos anos iniciais, o acadêmico tem a liberdade de escolher a instituição em que deseja atuar. Logo após a escolha, o acadêmico precisa elaborar o termo de compromisso e pegar as assinaturas dos responsáveis. E depois de tudo assinado, o acadêmico inicia os três dias de observação. Conforme Ghedin, Almeida e Leite (2008), a observação é um afazer complicado, porém necessário para romper a dicotomia entre teoria e prática. Pimenta e Lima (2005/2006) afirmam que no estágio o acadêmico aprende a profissão, a partir da imitação, observação e até mesmo da reelaboração dos padrões presentes na prática considerados como apropriados.

$\mathrm{O}$ acadêmico precisa atuar durante cinco dias, com isso precisa preparar um plano de aula ou projeto, com os conteúdos exigidos pelo professor titular da turma e adaptá-lo conforme a realidade da escola e da turma. Pimenta, Lima (2005/2006, p. 14) dizem que os estagiários precisam desenvolver "postura e habilidades de pesquisador a partir das situações de estágio, elaborando projetos que permitam ao mesmo tempo compreender e problematizar as situações que observam.” Projetos estes, que precisam se avaliados com o orientador antes de aplicá-los. Pois como Ghedin, Oliveira e Almeida (2015) relatam, o docente em formação está se preparando para realizar as tarefas práticas de sua profissão. E após isso, o acadêmico volta à escola para atuar.

Durante a atuação o professor orientador, escolhe um dia para acompanhar o estagiário na escola, e conforme Ghedin; Almeida e Leite (2008), o estágio oportuniza aos supervisores e aos acadêmicos uma relação enriquecedora, por conta das orientações e a visita que o professor faz nas escolas.

Saberes Pedagógicos, Criciúma, v. 3, n², julho/dezembro 2019.- Curso de Pedagogia - UNESC 
Após o acadêmico cumprir todas as etapas, a observação, a elaboração e execução do plano de aula ou projeto, é preciso fazer a socialização do estágio para a sua turma, além do relatório de estágio. Este relatório será entregue no final, acompanhado de outros documentos exigidos pelo curso de Pedagogia.

\section{METODOLOGIA, APRESENTAÇÃO E ANÁLISE DE DADOS}

A pesquisa tem como objetivo geral compreender quais as expectativas dos estagiários (as) do curso de Pedagogia da Unesc em relação ao trabalho pedagógico desenvolvido pelo professor (a) regente dentro da sala de aula nos anos iniciais.

A pesquisa científica na visão de Pinheiro (2010) é um processo de construção do conhecimento, tendo como metas principais gerar um novo conhecimento e confirmar ou contestar algum conhecimento já existente.

Quanto à abordagem, caracteriza-se como qualitativa que de acordo com Muylaert et al. (2014, p. 197) "preocupa em capturar um nível de realidade que não pode ser mensurado quantitativamente." Somado a isso, é uma pesquisa descritiva, pois visa explorar um dado fazendo uma descrição detalhada. Sendo assim, os dados coletados serão descritos, analisados e interpretados.

Desta forma, no início a pesquisa de campo seria através de uma entrevista semiestruturada, porém houve um receio dos entrevistados, alegando falta de tempo, e até mesmo a insegurança em relação à gravação. Sendo assim, foi realizada a pesquisa de campo, por meio de um questionário, que segundo Gil (2002, p. 114) "por questionário entende-se um conjunto de questões que são respondidas por escrito pelo pesquisado."

O público alvo foram dez acadêmicos (as) do curso de Pedagogia da Unesc, no município de Criciúma-SC, matriculados na sétima fase do curso, e cada participante responderam sete perguntas existentes no questionário. A escolha dos acadêmicos (as) ocorreu de forma aleatória, pelo fato de já terem vivenciado a prática do estágio obrigatório e assim contribuindo com a pesquisa. A coleta dos dados realizou-se no período de Setembro/2018. 


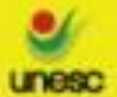

Com os dados coletados do questionário foi estabelecido algumas categorias de análise como: os sujeitos da pesquisa; a escola como lugar de formação de professores; o estágio obrigatório com (im)possibilidade de diálogo entre a universidade e escola.

Identificaremos os sujeitos com nomes fictícios, Isabella, Isadora, Jéssica, Joana, João, Letícia, Manuela, Maria, Patrícia, Sofia, para manter suas identidades preservadas.

\subsection{Os sujeitos da pesquisa}

Priorizamos trabalhar com acadêmicos (as) que estavam na sétima fase do curso de Pedagogia da Unesc, pois já haviam terminado o estágio obrigatório dos anos iniciais. Para conhecer os sujeitos da pesquisa estruturamos o quadro 1 abaixo.

\section{Quadro 1 - Números de participantes pesquisado}

\begin{tabular}{|c|l|l|}
\hline Total de participantes & Masculinos & Femininos \\
\hline 10 & 1 & 9 \\
\hline
\end{tabular}

Fonte: Dados de pesquisa 2018

Como podemos perceber, no quadro 1 a procura pelo curso de Licenciatura em Pedagogia, continua sendo por mulheres, mesmo com toda a ideologia de gênero existente, encontra-se um certo receio em homens ocupar esse cargo. Contudo, Vianna (2001, p. 93) confirma esse distanciamento da figura masculina "essa dicotomia cristaliza concepções do que devem constituir atribuições masculinas e femininas e dificulta a percepção de outras maneiras de estabelecer as relações sociais." Portanto, o que podemos ver é que a feminização ocorre pelos estereótipos criados, como o fato do cuidado, alimentação, entre outros.

\subsection{A escola como lugar de formação de professores}

Questionados sobre o entendimento por formação de professor, de acordo com a compreensão dos sujeitos pesquisados, são profissionais qualificados para atuar em diversas áreas. Nesse sentido a entrevistada Isadora descreveu "eu entendo por formação de Saberes Pedagógicos, Criciúma, v. 3, n², julho/dezembro 2019.- Curso de Pedagogia - UNESC 


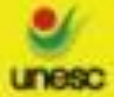

professores, um profissional formado com habilidades e competências para atuar dentro da sala aula ou em outras áreas que um professor pode atuar." Que vem ao encontro de Garcia (1999) onde cita que a formação dos professores precisa compatibilizar formação acadêmica e pedagógica, e nem sempre apresenta caráter de magistério. Ou seja, a formação do professor é um processo onde se adquire conhecimentos para a realização da docência. Esse processo ocorre em sua formação inicial, trocas de experiências, cursos de formação continuada, entre outros.

Dentro da mesma pergunta foi questionado como se forma um professor. Segundo os entrevistados, para se tornar um professor é preciso ingressar no ensino superior, conforme Maria "um docente para se formar em Pedagogia é necessário frequentar nível superior, ou seja, graduação em licenciatura [...].” Esta fala vem ao encontro de Tardif (2014) quando afirma que a graduação consiste em proporcionar aos futuros docentes um conjunto de conhecimentos. Pimenta e Lima (2005/2006, p. 11) contribuem dizendo "que a universidade é o espaço formativo por excelência da docência, uma vez que não é simples formar para o exercício da docência de qualidade e que a pesquisa é o caminho metodológico para essa formação [...]" Nesse sentido, é um período importante para a formação inicial do professor, e conforme Lombadi (2007, p. 119) torna-se "construtivo a universidade pensar seus programas visando a uma formação mais consistente e profícua em relação a um profissional competente, capaz de articular a teoria à prática docente."

Mas além da Graduação, os pesquisados acrescentaram que um docente também se forma no dia a dia da sala de aula, e fica evidente nas falas de: Patrícia, "o professor se forma todos os dias, dentro de suas práticas pedagógicas, criando autonomia profissional." $\mathrm{Ou}$ na fala de Joana, "professor se forma todos os dias, pois devemos estar em constante formação.” João, “formação de professor é a própria sala de aula, diga-se de passagem, uma das maiores formações que um professor possa ter, pois é onde o mesmo se depara com ' $\mathrm{N}$ ' perfis de alunos, seja econômico, familiar, cultural dentre outros, para analisar e ensinar." Todas essas falas vêm ao encontro de Nóvoa (2002, p. 64) ao dizer que "a formação passa pela experimentação, pela inovação, pelo ensaio de novos modos de trabalho pedagógico. E por uma reflexão crítica sobre a sua utilização. A formação passa, por processos de investigação, directamente [sic] articulados com as práticas educativas."

Saberes Pedagógicos, Criciúma, v. 3, n², julho/dezembro 2019.- Curso de Pedagogia - UNESC 
Isto é, a experiência na sala de aula, também é um modo de se formar professor, por estar criando sua autonomia profissional, o conhecimento da cultura escolar e da realidade dos alunos. Lima (2012, p. 39) complementa que estamos "constituindo essa identificação com a profissão docente no decorrer da vida, tanto pelos exemplos positivos, como pela negação de modelos. É nessa longa estrada que vamos constituindo maneiras de ser e estar no magistério."

Apenas uma entrevistada falou que o estágio obrigatório, é um modo de formação, e foi na fala de Maria “[...] os estágios obrigatórios são essenciais para se tornar um bom professor [...]" Como podemos perceber no decorrer desta pesquisa, a relevância do estágio supervisionado na formação do professor, e conforme Pimenta, Lima (2005/2006, p. 20) "o estágio, então, deixa de ser considerado apenas como um dos componentes e mesmo um apêndice do currículo, passando a integrar o corpo de conhecimentos do curso de formação de professores." Com isso, o estágio é significativo para o estagiário, pois compreende-se o todo, a escola, os profissionais, além de construir a sua própria personalidade profissional, desenvolvendo habilidades e competências.

Quando questionamos se a comunidade escolar tratou os acadêmicos como profissionais em formação, oito pesquisados falaram que sim e apenas dois disseram que não. As entrevistadas Patrícia e Jéssica, disseram que não foram vistas como profissional em formação, que a escola não estava aberta a diálogos. Segundo Nóvoa (2002), a comunicação entre os profissionais, é essencial. O estágio tem o objetivo de vivenciar a prática da profissão docente, porém é preciso ter o acolhimento de toda a comunidade escolar para que a experiência do estágio seja completa.

$\mathrm{Na}$ fala da entrevistada Sofia, ficou evidente a satisfação:

Durante todos os dias em que realizava o estágio, o que mais me surpreendeu foi o modo de como fui tratada. A todo momento, os profissionais da escola campo me proporcionaram momentos aos quais eu podia perceber a valorização de um estagiário nessa escola, podendo perceber que assim como a instituição formadoras promove práticas formativas, o estágio obrigatório se constitui como um dos elementos formativos essenciais na formação inicial do profissional docente.

E do acadêmico João, "a comunidade escolar entendeu o espaço que eu estava buscando na escola, o de realizar o meu estágio obrigatório, e contribuiu prontamente com Saberes Pedagógicos, Criciúma, v. 3, n², julho/dezembro 2019.- Curso de Pedagogia - UNESC 

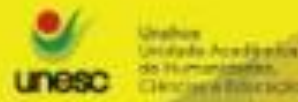

isso, abrindo as portas e estando sempre à disposição para o que eu precisasse.” Os outros entrevistados também, mostraram entusiasmo em relação ao tratamento que receberam, tiveram diálogos, compreensão, respeito, estavam sempre à disposição, sentiram-se valorizado, troca de experiências, e incentivo para continuar a profissão. Os entrevistados conseguiram aproximar-se da comunidade escolar, entender um pouco da realidade, e obtiveram experiências positivas. De acordo com Lima (2012, p. 93):

\begin{abstract}
A passagem dos estagiários pelo ambiente escolar constitui-se um fenômeno de influências recíprocas, no qual tantos os estagiários quantos os sujeitos envolvidos no contexto da instituição aprendem e ensinam sobre a profissão docente, bem como podem construir saberes decorrentes desse processo perceptivo.
\end{abstract}

Contudo, podemos perceber o quanto é importante estabelecer relação com toda comunidade escolar. Os estagiários se mostram motivados com o estágio obrigatório, fazendo que a sua formação obtenha mais significado para sua vida, e sua carreira docente.

Ao se referir sobre o planejamento dos professores e os recursos mais utilizados por eles, os entrevistados citaram o livro didático como o mais aplicado pelos docentes, e ministram suas aulas ainda na forma tradicional. Tardif (2014, p. 235) fala que esse tipo de concepção, "não é apenas profundamente redutora, ela também é contrária à realidade." Manuela, apontou que "o professor da escola campo planeja a aula de forma tradicional, sendo só em cima do livro didático, ou seja a memorização [...].” Já Isadora, mencionou que o professor até prepara as aulas em cima do livro didático, mas adapta a partir da realidade da turma. Desta forma, o que podemos perceber é que a concepção tradicional e o uso do livro didático, ainda está presente no dia a dia das escolas.

Lima (2012, p. 106) defende que "as ações de planejamento e avaliação se fazem necessárias para melhor compreensão do contexto e das particularidades da formação docente." Ou seja, é preciso preparar as aulas de acordo com a realidade existente de cada turma, diversificando as atividades, conforme Letícia:

Durante as observações foi possível notar que as aulas das professoras tanto do primeiro ano quanto do quarto ano dos anos iniciais, planejam suas aulas conforme a realidade e contexto de seus alunos. Com isso, também percebi que este planejamento busca outras possibilidades de aprendizagem e não ficam somente no que o aluno vive ou sabe.

Saberes Pedagógicos, Criciúma, v. 3, n², julho/dezembro 2019.- Curso de Pedagogia - UNESC 
Os entrevistados citaram alguns recursos além do livro didático, como: televisão, som, cartazes, balão, pátio, retroprojetor, revistas, jornais entre outros recursos. Conforme Pimenta e Lima (2017, p. 149), é preciso manipular diferentes "materiais didáticos que se adapte as condições da sala de aula as condições objetivas dos alunos." Portanto, a sala de aula é um espaço de conhecimentos, e cabe o professor preparar as aulas com recursos diversificados, envolvendo a participação dos alunos dentro das práticas pedagógicas.

\subsection{O estágio obrigatório como (im) possibilidade de diálogo entre a universidade e escola}

Durante o artigo falamos em teoria e prática, e sobre esta questão perguntamos se foi possível perceber essa relação entre as atividades propostas com as teorias estudadas durante o curso. Lima (2012) nos fez compreender que o estágio obrigatório é um período de pôr em práticas as teorias desenvolvidas durante o curso. $\mathrm{O}$ que podemos verificar com as respostas dos entrevistados foi que apenas seis pessoas conseguiram perceber. João disse:

\footnotetext{
Não. A professora seguia a linha tradicional, onde era copia e cola, atividades impressas, ou algo como: 'qual o título do texto?'. Na universidade aprendemos a transformar o tradicional, ensinar os alunos de uma forma mais lúdica, quando oportuno, para que o mesmo aprenda não por obrigação e sim por prazer, afim de sempre mais e mais perante o conhecimento. Os conteúdos, lá uma vez e outra, eram os mesmos que víamos na universidade, mas a forma de aplicá-los era a mesma citada anteriormente.
}

Podemos compreender referente esta fala, que para esta professora citada, teoria e prática andam distantes, pois a mesma ainda limita-se a uma prática carregada de vícios. Ghedin, Almeida e Leite (2008, p. 34) enfatizam que as práticas pedagógicas tradicionais "não tem permitido contribuir para análise crítica da prática docente em sala de aula e não tem conseguido formar uma cultura ou atitude docente que consiga superar a cultura escolar que ainda carrega vícios de uma perspectiva tecnicista e conservadora da educação." E assim, Pimenta, Lima (2017, p. 1730) descrevem que muitas vezes ocorre um "distanciamento entre os conteúdos trabalhados nas universidades e a realidade existente no contexto escolar." 

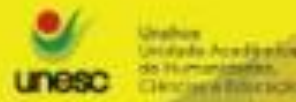

Contudo Leticia, disse que "foi perceptível a relação entre teoria (o que estudamos na graduação) e a prática (desenvolvimento das atividades dos profissionais do ambiente escolar) [...]." Ou seja, perante esta fala conseguimos identificar articulação da teoria e prática, estabelecidas pela professora.

Vimos que uma das etapas do estágio obrigatório é a observação, com isso o acadêmico fica atento aos detalhes, para depois fazer a sua atuação. Interrogamos se eles encontraram dificuldades e se conseguiram fazer a articulação da teoria e prática, alguns questionaram a falta de tempo para a realização dessa etapa, os imprevistos da própria instituição, medo e insegurança, de certa forma atrapalharam um pouco. Mas todos conseguiram fazer a articulação, mesmo alguns professores trabalhando na perspectiva tradicional. Destacando-se a escrita dos seguintes pesquisados:

\begin{abstract}
Obtive um pouco de dificuldade no estágio obrigatório dos anos iniciais, na disciplina de matemática, em que fui propor o método de Davydov com o apoio da reta numérica em multiplicações e divisões, porém como eles já haviam aprendido o método tradicional, foi pouco tempo para compreender. Outra questão foram os imprevistos próprios da escola, tais como provas trimestrais, cantar o hino junto com todos da escolas, entre outros. Sim, consegui relacionar os temas dados no estágio com os conteúdos aprendidos no curso, colocando em prática várias atividades, mesmo com algumas dificuldades. (MARIA)
\end{abstract}

Já João afirma, que a dificuldade encontrada foi no tempo, adaptar algumas atividades conforme a rotina da escola:

\begin{abstract}
A única dificuldade que encontrei foi a do tempo, pois planejava alguma atividade e tinha que adaptá-las para conseguir alcançar o meu objetivo final. Além do mais, às vezes era interrompido pela rotina da escola, essa que não foi me passada com antecedência ou acontecia de última hora. Sim, todos os conteúdos e atividades que aprendi na universidade e quis pôr na prática no estágio eu consegui. Claro, algumas atividades eu tive que adaptar, mas isso é normal, pois nenhuma escola é igual à outra e nenhum aluno é idêntico a outro, o que nos desafiam a estudar cada vez mais para ensiná-los.
\end{abstract}

Joana traz, que umas das maiores dificuldades foi a questão da resistência dos professores quando diz que:

Existe muita dificuldade seja pelo tempo que é oferecido e até mesmo pelas professoras titulares, que não querem que se faça algo novo, assim acabam

Saberes Pedagógicos, Criciúma, v. 3, n² 2, julho/dezembro 2019.- Curso de Pedagogia - UNESC 


\section{SABERES PEDAGÓGICOS}

Revista do Curso de Graduaçāo de Pedagogia - Unesc

ISSN 2526-4559

impedindo de nos proporcionar experiências novas. Consegui articular muitas coisas do curso em meu estágio.

Observamos nestas falas que ainda há uma resistência dos profissionais e até do próprio aluno em relação às práticas dos estagiários. Pode-se dizer que o acadêmico não está acostumado com essa rotina escolar, ou não são informados com antecedência e acabam sendo prejudicados em sua atuação.

De acordo com Pacchioni (2000, p. 68) "para o desenvolvimento de qualquer tarefa necessita-se de tempo, no estágio não é diferente.” Desta forma entende-se que para desenvolver um bom trabalho necessita de tempo, e as vezes se torna pouco, para a realização das práticas pedagógicas no estágio obrigatório. Além disso, as aulas do curso de Pedagogia são muito importantes para obter essa relação teoria e prática dentro do estágio obrigatório, que de acordo com Lombadi (2007, p.119) oportuniza ao acadêmico "simulações de situações existentes em sala de aula, experienciar comportamentos e estratégias de ensino, possibilitando-lhe pensar na própria postura, quando estiver diante de tais situações e nas possíveis atitudes que irá tomar frente a problemas reais.” Sendo assim, o estágio é uma maneira de relacionar os conhecimentos teóricos com a prática, envolvendo os processos de ensino e aprendizagem.

O estágio obrigatório é um elemento importante na formação do professor. Questionados sobre as contribuições referentes ao estágio, os acadêmicos responderam ser a experiência adquirida dentro da sala de aula. Conforme Lombadi (2007, p. 120) "é o espaço em que o futuro professor vislumbra a prática profissional." Visto que, o estágio contribui para a experiência profissional, também é possível verificar se é a escolha certa para exercer como carreira. Podemos perceber nas respostas, como a de Jéssica quando afirma que o “estágio, contribuiu como prática dentro da sala de aula, e para saber se era isso que eu queria para meu futuro." Pacchioni (2000) deixa isso evidente quando cita que a prática do estagiário na escola pode proporcionar a comprovação de sua profissão.

Quando questionados em relação às expectativas que o estágio obrigatório dos anos iniciais proporcionou, os entrevistados conseguiram atingir os objetivos, articularam teoria e prática, superaram o medo a insegurança. Nesta perspectiva, (Ribeiro e Araújo, 2017, p. 1727) contribuem dizendo que "o estágio supervisionado, enquanto disciplina obrigatória

Saberes Pedagógicos, Criciúma, v. 3, n², julho/dezembro 2019.- Curso de Pedagogia - UNESC 

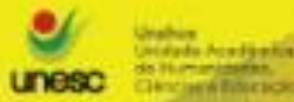

nos cursos de licenciaturas deve ser apresentado como uma possibilidade de levar os alunos a conhecerem, entenderem e vivenciarem a realidade da educação básica." Sendo assim o estágio proporciona ao aluno essa vivência na prática, e assim superando as expectativas dos acadêmicos, que quando começam a atuação tem um pensamento diferente de quando terminam o estágio obrigatório. Isso fica notório nas respostas:

O estágio obrigatório supervisionado dos anos iniciais superaram minhas expectativas, pois o que eu aprendi durante a graduação, consegui perceber muitas delas na escola campo. Tendo em vista, os horários das aulas das professoras que são bem corridos, as exigências diárias, as profissionais precisam lidar com os alunos, pais e mesmo assim procuram desenvolver com êxito sua profissão. E isso foi o que mais me impressionou durante minha presença no campo educacional. (LETÍCIA)

Manuela diz que além de superar suas expectativas conseguiu superar seus medos. "As expectativas foram muitas, superei meu medo e insegurança mesmo com todos os impasses, consegui dominar os conteúdos e aprendi muito com os profissionais mais experientes."

E assim, o estágio obrigatório é significativo para os acadêmicos, superando as expectativas e proporcionando muitos aprendizados, experiências com os alunos e a comunidade escolar, sendo levada por toda a trajetória profissional na vida dos acadêmicos. É o que Ribeiro e Araújo (2017, p. 1732) salientam quando dizem que “o estágio supervisionado é um processo que deve proporcionar aos licenciandos, coletivamente com outros sujeitos, experiências significativas, formadoras e, portanto, transformadoras a partir das múltiplas relações estabelecidas."

\section{CONCLUSÃO}

A pesquisa foi realizada, visando compreender as expectativas dos estagiários (as) do curso de Pedagogia da Unesc em relação ao trabalho desenvolvido pelo professor (a) dentro da sala de aula nos anos iniciais, e com isso foi possível compreender que o estágio é uma etapa relevante para a formação profissional do acadêmico (a). 
Os objetivos desta pesquisa foram alcançados, o estágio obrigatório contribui para a formação do professor e existem dificuldades para a execução do mesmo. Perante o trabalho pedagógico dos professores da escola campo, ainda não atende as expectativas dos acadêmicos. Com isso, o problema foi respondido, visto que o professor da escola campo, ainda trabalha na linha tradicional, muitas vezes não relacionando teoria e prática. Sendo assim, a conclusão é de caráter provisório, pois estamos sempre em busca de novas pesquisas para colaborar com o conhecimento.

Contudo, no decorrer dessa pesquisa foi possível verificar através dos estudos, que o estágio obrigatório dentro do curso de licenciatura em Pedagogia é visto como um período formativo, quando teoria e prática se ligam de modo mais orgânico. E que a formação do professor é um processo que acontece durante toda sua trajetória docente, criando assim a sua própria identidade profissional.

Portanto, o estágio supervisionado obrigatório e não obrigatório é um momento de relacionar com outros sujeitos envolvidos no processo de ensino e aprendizagem, trocando experiências e diálogos, compreendendo melhor a realidade da instituição em que irá atuar. Uma vez, que o ensino não pode ser considerado individual, mas no coletivo. Da mesma forma, é um modo de aproximar da prática docente, relacionando o que aprendeu na universidade com o dia a dia das escolas.

Em relação às expectativas dos licenciados em Pedagogia referente ao estágio supervisionado, aponta-se a importância em relacionar teoria e prática dentro da sala de aula. Porém, ainda encontramos práticas tradicionais longe da realidade dos estudantes que levam os alunos a memorização.

Contudo, o estágio obrigatório é um meio de construir experiência profissional, ou seja, é a oportunidade que os acadêmicos têm de sentirem-se professores, criando sua autonomia profissional. E assim, com o conhecimento visto dentro da universidade, o acadêmico consegue desenvolver diferentes práticas, promovendo um ensino de qualidade à todos os sujeitos envolvidos.

A realização de uma pesquisa é uma tarefa que necessita dedicação e com isso existem dificuldades durante este processo. A angústia e a ansiedade foram os sentimentos o que mais afetaram na hora da produção do trabalho escrito.

Saberes Pedagógicos, Criciúma, v. 3, n², julho/dezembro 2019.- Curso de Pedagogia - UNESC 
O aprofundamento desse tema permitiu conhecer melhor sobre o estágio obrigatório e a importância que ele tem, dentro da formação do professor. É uma oportunidade, de relacionar teoria e prática, adquirindo habilidades e experiências dentro da sala de aula, e assim obtendo um novo olhar referente ao estágio supervisionado.

Enfim, o estágio é extremamente importante para o acadêmico perceber que o professor está sempre em processo de formação, e com isso é preciso entender a realidade escolar existente e repensar na prática pedagógica para que a mesma possa contribuir para um ensino de qualidade a todos os alunos.

\section{REFERÊNCIAS:}

ALMEIDA; Maria de Lourdes Granato. Licenciatura em Pedagogia estágio supervisionado: um olhar reflexivo. In: CARVALHO, Gislene T. R. D; UTUARI, Solange (orgs). Formação de professores e estágios supervisionados: alguma veredas. Andross, 2007. $39-47$ p.

BRASIL. CNE/CP. No 5, DE 13 de dez. de 2005. Disponível em:

<http://portal.mec.gov.br/cne/arquivos/pdf/pcp05_05.pdf>. Acesso 10 ago. 2018.

GARCIA, Carlos Marcelo. Formação de professores. Para uma mudança educativa. Porto: Porto Editora, 1999.

GHEDIN, Evandro; OLIVEIRA, Elisangela S. de; ALMEIDA, Whasgthon A. de. Estágio com pesquisa. São Paulo: Cortez, 2015. 279 p.

ALMEIDA, Maria Isabel de; LEITE, Yoshie Ussami Ferrari. Formação de

professores: caminhos e descaminhos da prática. Brasília: Liber Livro Editora, 2008. 142 p.

GIL, Antônio Carlos. Como elaborar projetos de pesquisa. 4. ed. São Paulo: Atlas, 2002. 175 p. Disponível em:

$<$ https://professores.faccat.br/moodle/pluginfile.php/13410/mod_resource/content/1/como_ela borar_projeto_de_pesquisa_-_antonio_carlos_gil.pdf>. Acesso em: 13 jun. 2018.

LIMA, Maria Socorro Lucena. Estágio e aprendizagem da profissão docente. Brasília: Liber Livro, 2012. 171 p.

Reflexões sobre o estágio supervisionado na formação de professores. Revista

Diálogo Educ., Curutiba, v. 8, n.23, p. 195-205, jan./abr. 2008. Disponível em: 


\section{SABERES PEDAGÓGICOS}

Revista do Curso de Graduaçāo de Pedagogia - Unesc

ISSN 2526-4559

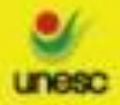

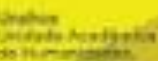

http://nead.uesc.br/arquivos/Biologia/mod5bloco4/texto-reflexoes_sobre_estagio-e-praticade-ensino.pdf. Acesso em: 04 set. 2018

LOMBADI, Roseli Ferreira. Estágio supervisionado: importante na e para a formação do professor. In: CARVALHO, Gislene T. R. D; UTUARI, Solange (orgs). Formação de professores e estágios supervisionados: algumas veredas. Andross, 2007. 115 -

MUYLAERT, Camila Junqueira et al. Entrevistas narrativas: um importante recurso em pesquisa qualitativa. Rev Esc Enferm Usp, São Paulo, p.193-199, 2014. Disponível em: 〈http://www.scielo.br/pdf/reeusp/v48nspe2/pt_0080-6234-reeusp-48-nspe2-00184.pdf〉. Acesso em: 09 set. 2018

NÓVOA, António. Formação de professores e profissão docente. Portugal: Universidade de Lisboa, 1995. 27 p. Disponível em:

〈http://repositorio.ul.pt/bitstream/10451/4758/1/FPPD_A_Novoa.pdf.>. Acesso em: 20 abr. 2018.

Formação de professores e trabalho pedagógico. Lisboa: Educa, 2002, p. 88.

PACCHIONI, Margareth Maria. Estágio e supervisão uma reflexão sobre a aprendizagem significativa. São Paulo: Stiliano, 2000. 160 p.

PIMENTA, Selma Garrido. O estágio na formação de professores: Unidade teoria e prática. 11. ed. São Paulo: Cortez, 2012. 224 p.

$310 \mathrm{p}$.

LIMA, Maria Socorro Lucena. Estágio e docência. 8. ed. São Paulo: Cortez, 2017.

LIMA, Maria Socorro Lucena. Estágio e docência: diferentes concepções. Revista Poíesis. 2005/2006. Volume 3, 24 p. disponível em:

<https://www.revistas.ufg.br/poiesis/article/view/10542/7012> Acesso em: 01 ago. 2018.

PINHEIRO, Jose Mauricio dos Santos. Da iniciaçao cientifica ao tcc: uma abordagem para os cursos de tecnologia. Rio de Janeiro: Ciência Moderna Ltda, 2010. 162 p.

RIBEIRO, Luis Távora Furtado; ARAÚJO, Osmar Hélio Alves. O estágio supervisionado: Fios, desafios, movimentos e possibilidades de formação. Revista Ibero-Americana de Estudos em Educação, Araraquara, jul-set 2017, v. 12, n. 3, p. 1721-1735. Disponível em: $<$ https://periodicos.fclar.unesp.br/iberoamericana/article/view/10280> Acesso em: 04 de set. 2018

TARDIF, Maurice. Saberes docentes e formação profissional. 17. ed. Rio de Janeiro: Vozes, 2014. 328 p.

UNESC. Regulamento de estágio do curso de Pedagogia Licenciatura da Unesc. Criciúma, 2009, Disponível em: 
<http://www.unesc.net/portal/resources/official_documents/5166.pdf?1300279567>. Acesso 10 ago. 2018.

VIANNA, Cláudia Pereira. O sexo e o gênero da docência. 2001, 81-103 p. Disponível em: <http://www.scielo.br/pdf/cpa/n17-18/n17a03>. Acesso 27 set. 2018. 